\title{
Long Term Natural Alternatives for Halogenated Refrigerants - Hydrocarbons
}

\author{
Leelananda Rajapaksha
}

\begin{abstract}
Hydrofluorocarbons ( $H F C S$ ) are being used presently as medium term alternatives for environmentally damaging chlorofluorocarbon refrigerants (CFCs). However, higher global warming potentials (GWP) of HFCs are still a serious environmental concern though they do not contribuie to stratospheric ozone depletion. When it comes to finding refrigerants that do not deplete the ozone layer and has minimal direct global warming potential, natural fluids stand out among the potential. alternatives. Among natural refrigerants hydrocarbons $(\mathrm{HC})$ is one category with no ozone depleting potential and with minimal GWP potentials. Besides, compared with CFCs and HFCs, hydrocarbon show better heat transfer performance, blend well with existing lubricants and require relatively lower amounts of system charge. However, flammability of HCs raise concerns over their use in refrigeration systems. Yet, HCs are gaining increased recognition in many areas of vapour compression refrigeration as a long term refrigerant. This paper discusses heat transfer and retrofit aspects, and issues in international standards for the use of flammable HCs in refrigeration and heat pump systems
\end{abstract}

Keywords: Hydrocarbon, refrigeration, heat transfer, retrofit, system charge

\section{Introduction}

By the end of the $20^{\text {th }}$ centaury halogenated refrigerants have proved the undesirable implications they have on the environment. A more sensible approach to selection of environmentally benign alternative refrigerants would be to consider fluids that occur in nature. Historically, hydrocarbons (HCs) were among the first natural refrigerants to be used. Yet, their flammability associated safety issues paved the way for more inert halogenated fluids including chlorofluorocarbons (CFCC) [1. However, with the disclosure of the potential environmental damages the continued use of halogenated refrigerant could cause, and having understood the damages already done, natural refrigerants are in the spot light of refrigerant research

With this renewed interest on natural refrigeranis, ammonia, carbon dioxide and hydrocarbons (HCs) stand prominently as potential candidates. Among these, HCs posses zero ozone depletion potentials (ODP) and extremely low global warming potentials (GWP). Further, HCs in general show higher system efficiencies, reduced charge sizes, good miscibility with mineral oils (no need for synthetic oils), lower compressor discharge tcmperatures, and better heat transfer within heat exchangers compared to many halogenated refrigerants that could be replaced with HCs [1].

The main advantages of $\mathrm{HCs}$, compared to the other natural refrigerants, are that they are in many respects very similar to the halogenated refrigerants the industry is already familiar with. For the use of $\mathrm{HCs}$, no major changes in the refrigeration systems or components are needed. Additionally it is known that mineral oil, which is widely used with halogenated refrigerant, show very good miscibility with HCs and can be used as compressor lubricant [2]. With all these desirable characteristics and features for application of HCs in vapour compression refrigeration, the only practical factor against is their safety concerns arising from flammability. Under such conditions, installation practices and safery guide lines, handling procedures etc, covering the use of relatively large quantities of HCs in many potential applications, are required from a technical point of view [3]. However, the obstacle of flammability that negatively affect the use of $\mathrm{HCs}$ in refrigeration systems is gradually dealt with in terms of regulations

Eng.(Prof.) Leelananda Rajapaksha, MIE(Sri Lankn), MHAR, CEng., MIMechE, BScEng. (First Class Hons), MEng, PhD. Associate Professor, Department of Mechanical Engincering, Faculty of Engineering, University of 
making way for the use of these natural refrigerants. For example reducing system charge through the use of indirect systems and compact heat exchangers, placing of the units outdoor, use of safety warning systems such as hydrocarbon sensors, alarms and forced ventilation are all steps which are being considered and being implemented in certain parts of the world to reduce the risks under normal operation of refrigeration system using HCs.

With all the envirommentally friendly features together with other desirable fund characteristics (such as being non-toxic, nonrestricted availability etc.) HCs offer long term alternatives for many of the medium term halogenated refrigerants and refrigerant mixtures (i.e. those with higher degrees of undesirable environmental damages) being used at present. This paper presents an account on the use of hydrocarbons in vapour compression refrigeration systems; from domestic refrigerators to commercial heating/cooling systems. A.lso, trics to highlight the present regulatory aspects associated with the use of flammable hydrocarbon in refrigeration systems that encourage the use of these fluids

\section{Hydrocarbon refrigerants - properties and flammability}

The hydrocarbons of interest and that suit refrigeration applications in general are ethane ( $\left.\mathrm{R} 170, \mathrm{C}_{2} \mathrm{~F}_{6}\right)$, propane ( $\mathrm{R} 290, \mathrm{C}_{3} \mathrm{H}_{8}$ ), butane ( $\mathrm{R} 600, \mathrm{C}_{4} \mathrm{H}_{10}$ isobutane, $\mathrm{R} 600 \mathrm{a}$ ) and propylene ( $\mathrm{R}$ 1270, $\mathrm{C}_{3} \mathrm{H}_{6}$ ). Isobutane (R600a) is the most frequently used hydrocarbon refrigerant [3]. In Europe it is the totally dominating refrigerant in household refrigerators. In 2004, 33\% of the world production of domestic refrigerators and freezers used pure isobutane, or isobutane blends [4] I'ropane (R290) and propene (propylene, R1270) have also been used in air conditioners and in commerial refrigeration systems. In addition to single component pure isobutane, propane and propene blends of isobutane/propane and propane/ethane to match the vapour pressure curves of $\mathrm{R} 12 / \mathrm{R} 134 \mathrm{a}$ and $\mathrm{R} 22 / \mathrm{R} 407 \mathrm{C}$, respectively are also available presently Butane (R600) has also been under discussion, but has not been used commercially to the extent of isobutane though its properties are quite similar to those of isobutane. Pentane and isopentane have been considered for use in centrifugal systems to replace R11 [5]

When using hydrocarbon refrigerants it is essential to use refrigerant grade products only. Commercial grade hydrocarbons contain significant quantities of sulphur, water, and other impurities and could contribute to oil degradation, shorten the compressor life and invalidate any warranties. Also, unlike commercial liquid petroleum gases (LPG) hydrocarbon refrigerants are not odourised. Another problem with commercial LPG is that the composition of any specific hydrocarbon can be variable thus drastically changing the properties of the refrigerant from cylinder to cylinder

Table 1 presents a summary of few selected cases where some of the recent refrigerants and mixtures (HCFCs and HFCs) would have replacement from hydrocarbons for different cooling or heating applications.

Table 1 - Hydrocarbon replacement for halogenated refrigerants and mixtures [6]

\begin{tabular}{|c|c|c|}
\hline $\begin{array}{l}\text { Refigerant } \\
\text { ormixture }\end{array}$ & $\begin{array}{c}\text { Replacement } \\
\text { HCs }\end{array}$ & Application range \\
\hline R12, [R134a & $\begin{array}{l}\text { R600a } \\
\text { (Isobutane) }\end{array}$ & $\begin{array}{l}\text { Domestic appliances } \\
(\mathrm{H}, \mathrm{M})\end{array}$ \\
\hline $\begin{array}{l}\text { R22, R+OAA, } \\
R+07 \mathrm{C}, \\
\text { R507A }\end{array}$ & $\begin{array}{l}\text { R2o0 } \\
\text { (Propane) }\end{array}$ & $\begin{array}{l}\text { Commercial and industrial } \\
\text { heezers, air-conditioning, } \\
\text { heat pumps }(\mathrm{H}, \mathrm{M}, \mathrm{L})\end{array}$ \\
\hline $\mathrm{K} 12, \mathrm{R} 134 \mathrm{a}$ & $\begin{array}{l}\text { R6003a/R290 } \\
\text { Mixture }\end{array}$ & $\begin{array}{l}\text { Commercial, automotive, } \\
\text { domestic }(\mathrm{H}, \mathrm{M}, \mathrm{L}, \mathrm{)}\end{array}$ \\
\hline $\begin{array}{l}\mathrm{R} 22, \mathrm{R} 404 \mathrm{~A}, \\
\mathrm{R} 40 \% \mathrm{C}, \\
\mathrm{R} 5 \mathrm{~T} / \mathrm{A}\end{array}$ & $\begin{array}{l}\text { R1220 } \\
\text { (Propylene) }\end{array}$ & $\begin{array}{l}\text { Industrial and process } \\
\text { refrigeration, } \\
\text { air-conditioning, heat } \\
\text { pumps, chillers }(\mathrm{H}, \mathrm{M}, \mathrm{L})\end{array}$ \\
\hline $\begin{array}{l}\mathrm{R} 13, \mathrm{R} 23, \\
\mathrm{R} 503\end{array}$ & $\begin{array}{l}\text { R170 } \\
\text { (Ethane) }\end{array}$ & Cascade systems (L) \\
\hline $\begin{array}{l}\mathrm{R} 22, \mathrm{R} 404 \mathrm{~A}, \\
\mathrm{R} 407 \mathrm{C}, \\
\mathrm{R} 50 \% \mathrm{~A}\end{array}$ & $\begin{array}{l}\text { R290/R170 } \\
\text { Mixture }\end{array}$ & $\begin{array}{l}\text { Commercial, industrial \& } \\
\text { process refrigeration, } \\
\text { air-conditioning, heat } \\
\text { pumps, chillers }(\mathrm{H}, \mathrm{M}, \mathrm{L})\end{array}$ \\
\hline
\end{tabular}

H- high temperature, L-Low temperature, M- Medium temperature. The boundary of range of temperature identifying high, medium, and low temperature depend on the application (air conditioning, refrigeration or heat pump). In industrial/commercial refrigeration lowtemperature refrigerator refers to when the product is firozen say down to about -30 to -50 " $C$, nediumtemperature opplies when the product is kept just above treezing, and high remperature refers to above zero applicutions in general.

Like many commonly used commodities such as petrol, natural gas and electricity, the use of IIC refrigerants requires common sense and observance of adequate safety procedures. It is important to understand that the volume of hydrocarbon refrigerant involved in a motor vehicle air conditioners and domestic 
refrigeration systems are very small, perhaps less than $250 \mathrm{~g}$ depending on the system concern. However, commercial and industrial refrigeration systems are more likely to have amounts of hydrocarbons that could pose real safety threat, for example when system charge exceeding $2.5 \mathrm{~kg}$.

Table 2 provide a list of selected thermalphysical properties of selected HCs where those for some selected HFCs/HCFCs are given for the purpose of comparison.

Table 2 - Selected properties of refrigerants

$[6,7,8]$

\begin{tabular}{|c|c|c|c|c|c|}
\hline & R170 & $\mathrm{R} 290$ & $\mathrm{R} 600 \mathrm{a}$ & R1270 & R134a \\
\hline $\operatorname{NBP}\left({ }^{\circ} \mathrm{C}\right)$ & -88.8 & -42.1 & -11.7 & -47.7 & -26.1 \\
\hline$T_{e r}\left({ }^{\circ} \mathrm{C}\right)$ & 32.2 & 96.7 & 135.0 & 91.8 & 101.1 \\
\hline$P_{c r}($ bar $)$ & 48.9 & 42.3 & 36.5 & 46.2 & 40.6 \\
\hline $\mathrm{h}_{\mathrm{Cg}: 25^{\circ} \mathrm{C}(\mathrm{kJ} / \mathrm{kg})}$ & 299 & 342 & 332 & 338 & 177.8 \\
\hline$M(\mathrm{~kg} / \mathrm{kmol})$ & 30.1 & 44.1 & 58.1 & 42.1 & 102.0 \\
\hline LFL (\% vol) & 3.2 & 2.3 & 1.8 & 2.0 & NF \\
\hline
\end{tabular}

$\mathrm{T}_{\mathrm{cr}}, \mathrm{P}_{\mathrm{cr}}$ - Critical temperature and pressure respectively, NBP - normal boiling point temperature (at $1 \mathrm{~atm}$ ),

$h_{i g}$ - latent heat, $M$ - Molar mass, LFL - Lower flammability linit, NF - non flammable

As given in Table 2, the lower flammability limits of HCs are smaller such that in case of a leak the $\mathrm{HC}$ concentration in the surrounding space could approach flammable limits if the system was in a smaller enclosed space such as a small room. This is the very issue that needs to be adequately covered, and the user be aware of, in the use of HCs in direct refrigeration systems. In the case of indirect system, where the refrigeration plant stays outside and coupled to the application via a secondary heat transfer fluid, though the flammability risk is there to a lesser extent, the chances of personal damages are reduced.

\section{Two phase heat transfer}

Heat transfer behaviour of flammable HC refrigerants show the typical trends of nucleate boiling, flow boiling and flow condensing with vapour pressure as those observed with $\mathrm{CFC} / \mathrm{HCFC}$ refrigerants. However, a general observation is that, with many $\mathrm{HCs}$, the heat transfer performances could be better when compared with halogenated refrigerant under similar conditions. Heat transfer and pressure drop studies of hydrocarbons are presently gaining ground as $\mathrm{HCs}$ secure places in different sectors of refrigeration industry. Therefore, availability of documented reliable results and data covering these aspects of $\mathrm{HCs}$ are not commonly accessible/available yet as those for halogenated refrigerants. Similarly, available information on the effects of oil on heat transfer is scarce, but studies in this area are essential as pressure drop resulting from the presence of oil tend to reduce the HTCS considerably, and vary from one $\mathrm{HC}$ to another [9], and could compromise the delivered performances.

- Flow boiling and condensation

Since most of the hydrocarbons have similar, or somewhat superior in some cases, thermophysical properties compared with conventional fluorocarbon refrigerants, there are no significant differences in physical phenomena of heat transfer. However, in general $\mathrm{HCs}$ tend to show relatively higher HTCS compared to halogenated refrigerants under similar conditions [9]. Yet, with enhanced surfaces whether the HTC is higher or lower than those of halogenated refrigerants could depend on the magnitude of pressure drops and the effect of the oil [2].

In smaller serpentine tubes ( $2.5 \mathrm{~mm}$ diameter) the flow boiling HTC of R290, R290/R600 $(55 / 45 \%)$ and $R 600$ are about $71 \%, 67 \%$ and $33 \%$, respectively higher than those for R-134a at the same saturation temperature. This indicates that the exchanger sizes of new refrigeration, systems using R290, R600 or R290/R600 could be smaller and the system performance would be better [10]. In comparison with R22, R290, R600a and R1270 all show higher local evaporating heat transfer coefficients in plain tubes, where average evaporating HTC are $67.7 \%, 55.4 \%$ and $72.3 \%$ higher respectively than that of $R 22$. [11].

In plain tube two phase heat transfer, the average condensing HTC of R290, R600a and R1270 are about $60 \%, 68 \%$ and $70 \%$ respectively higher than that of $\mathrm{R} 22$. The average condensing HTC increased as the mass flux increased in the range $50-200 \mathrm{~kg} / \mathrm{m}^{2}$ for all three HCs [11]. The condensation HTC of R600, R290/R600 (50/50 \% wt), R290, in small serpentine tubes are about 155\%,124\% and $89 \%$ larger than that of R134a. Further, the trends of variation of HTCs with vapour quality and mass flux show common trends with R134a [12].

- Pressure drops 
The typical fluid behaviour of evaporation and condensation pressure drop with mass flow rate could be observed with HCs.; i.e. pressure drop increase with increasing mass flow rate $[12,13]$. However, in terms of magnitudes, it has been found that the two-phase flow frictional pressure drop for R600, R290/R600 and R290 are about 1.41-1.60-fold, 1.32-1.50fold and 1.22-1.40-fold smaller as compared with that for R134a, respectively [10]. Further, the pressure drop increases as the refrigerant mass flow rate and the vapour quality increase [12]. Moreover, pressure drops during evaporation and condensation of $\mathrm{HCs}$ increase with the addition of a lubricant $[13,14]$.

\section{- Effect of oil on heat transfer}

The general observation of the effect of lubricant is that the evaporation HTC improves at small oil concentrations up to about $1 \%$, and the HTC degrade at higher oil concentrations as well as at higher vapour qualities.

During flow boiling R600a, and R290 in small diameter $\left(2.46 \mathrm{~mm}, 100-320 \mathrm{~kg} / \mathrm{m}^{2} \mathrm{~s}\right)$ tubes significant degradation of HTC occurs when oil concentration exceeds $1 \%$, and the effect is considerably higher when the vapour quality reaching 0.7 and over. These two HCs showed improvement in HTC at oil concentrations below $1 \%[14]$.

Flow condensing HTC of R290, and R600a in serpentine small-diameter $(2.46 \mathrm{~mm})$ tubes decreased in the range $3.3-18.9 \%$ and $4.4-17.6 \%$ compared to values without oil, respectively as the oil concentration increases up to $5 \%$ [13].

\section{System Retrofits with HCs}

Numerous attempts of charging different existing refrigeration systems with HCs (i.e. HC retrofits) are found in relevant literature. Among these domestic refrigerators, freezers, small air conditioners etc. take a prominent place due to smaller quantity of refrigerant charge involved. Further another desirable feature for retrofit (e.g. R22 system with R290) is that the requirement for hardware changes are practically none in many cases. Further such conversions are of very low cost compared to system conversion requiring major hardware changes and the resulting performances are on average stay within $90 \%$ of those of the original system $[15,16]$.
Fairly large number of retrofit attempts of domestic refrigerators with different hydrocarbon refrigerants can be found in literature $[15,17,18,19$ for example]. A domestic refrigerator usually has a small amount of refrigerant charge. A fact which encourage the retrofit of existing domestic refrigerant with $\mathrm{HCs}$ as the scale of flammability risk is relatively lower with smaller amount of $\mathrm{HCs}$ in the system. Even in the event of a leak of $\mathrm{HC}$, the quantity may not raise the concentration up to lower flammability level depending on the air volume of the room concerned. Further, with relatively better heat transfer performances and similar vapour pressures as of replacing halogenated refrigerants, the chances of restoring the capacity (with both minimum cost and hardware changes) with HCs is another aspect that encourages conversion of domestic refrigerator to HCs.

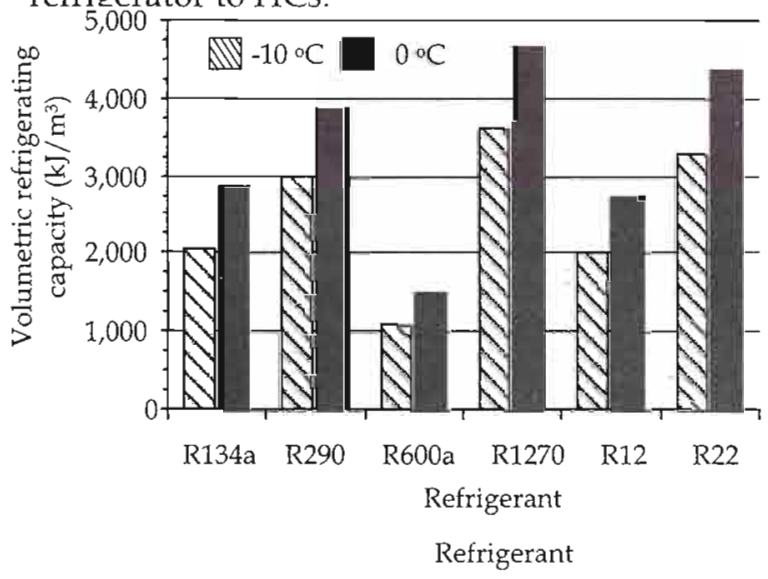

Figure 1 - Volumetric refrigerating capacities

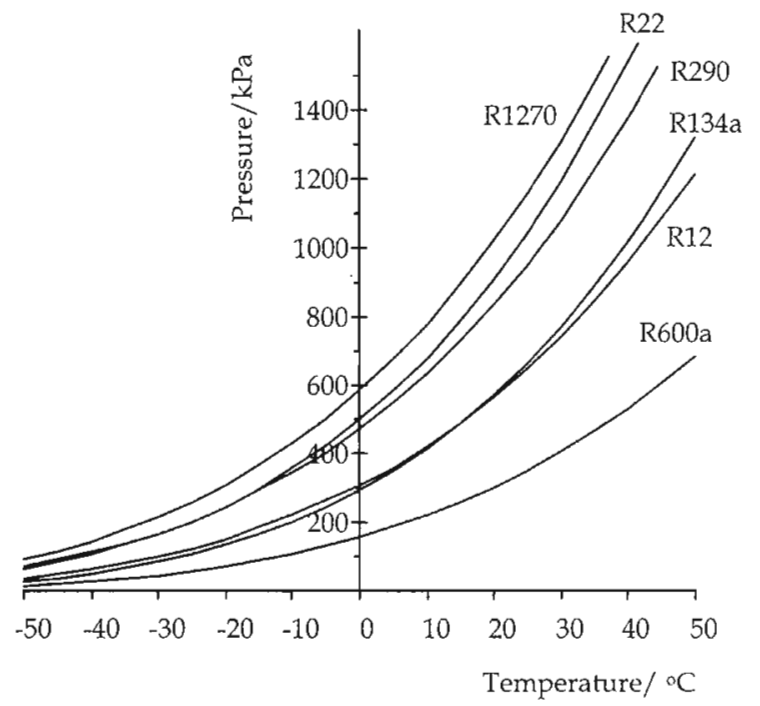

Figure 2 - Saturation vapour pressure 
Further as can be seen in Fig 1 and 2, HCs, such as R290, R600a and R1270 appear to make good replacements for halogenated refrigerants R22 R134a. When the volumetric refrigerating capacity and vapour pressures of R290 and R1270 are considered, it can be seen that these HCs can practically be used as a drop in replacement for $\mathrm{R} 22$, and to a lesser extent with R134a, as the volumetric refrigerating capacities (which decides the required volume flow rate of the compressor, or in other words the physical size of the compressor) and saturation pressures are quite of the same order. These, when combined with good behaviour with mineral oils, make these HCs very good low cost replacement refrigerants for $\mathrm{R} 22$, and even for R134a and R12 at some compromise of performances; capacity particularly.

The performance of LPG (24.4\% propane, $56.4 \%$ butane and $17.2 \%$ isobutane ) on a refrigerator designed for R12 (with hermetically sealed reciprocating compressor, $0.21 \mathrm{~kg}$ of $\mathrm{R} 12$ charge, 320 litre gross capacity, -10 to $-30 \mathrm{C}$ evaporator operating temperature, $150 \mathrm{~W}$ nominal input power at $240 \mathrm{~V}$ ) reported to be promising. Without any modification in the retrofit exercise the system has worked for over two years and delivered comparative COPs and cooling capacities as of the original system [18].

A small-capacity refrigerator designed for $R 134 a$, when retrofitted with a mixture of $R 290$ and $R 600 \mathrm{a}$ ( $55 / 45$ by mass), took approximately half the amount of charge it was originally charged with R134a, which is encouraging in the context of using HCs. Fuxther, the capillary tube needed to be cxtended by about $500 \mathrm{~mm}$ and the volume flow capacity of the compressor increased more than that of the original system to obtain optimized performances with the $\mathrm{HC}$ mixture. With such modifications, the retrofitted system delivered about $29 \%$ higher cooling capacity at about $12 \%$ lower power consumption compared to original R134a system [19]

In a drop-in retrofit of an existing $R 22$ window air conditioner with propane ( $\mathrm{R} 290)$ it has been observed that the cooling capacity of the system decreased by about 7\%, to $9 \%$ in comparison with those with R 22 running in low and high mode of operations respectively. However, the discharge pressure showed a reduction of in the range $14-18 \%$, with a corresponding reduction in electricity consumption in the range $12 \%$ to $14 \%$, for the low and high modes respectively.
These accompanied improvements of COP in the range $3 \%$ to $7 \%$ for the low and high modes respectively [16]. Similar trends of performances are reported in other retrofit exercise involving window air conditioners with R 290 [15].

In an on-farm tial for drop-in HC replacements of R22 in milk silo refrigeration systems a mixture of propane and ethane (Care-50) reduced energy use by $6-8 \%$, and showed similar system cooling capacity relative to $R 22$. With propane, energy use decreased by $5 \%$ but cooling capacity was $9 \%$ lower The retrofits were simple and low cost because no alterations to the systems other than change in refrigerant and appropriate safety labelling and documentation were made. For most farms, the outside refrigeration system location and small charge mean the lower risk associated with the use of HCs. The low retrofit cost, low environmental impact, mineral oil compatibility, almost similar cooling capacity as of the original system and controllable flammability risks mean that the propaneethane mixture is an attractive replacement for R22 for dairy farms [16].

\section{International standards}

Global standards applicable to refrigeration systems and their installation come mainly from two organisations: the Interrational Standardisation Organisation. (ISO) and the International Electrotechnical Commission (IEC). To provide an idea of numerous standards that concerns refrigeration systems, a list of few selected applicable standards for the use of hydrocarbon in refrigeration and air conditioning system is given in Appendix 1.

However, concerning the use of $\mathrm{HCs}$ in refrigeration systems the most important international standards are ISO 5149, ISO 817, IEC 60335-2-24, IEC 60335-2-40 and IEC 603352-89. In addition to these, most European counties have their own national standards developed based on international standards and adopted to match local conditions, which are then incorporated with the legal system to make sure the industry adhere to the conditions stipulated. This in a way could be treated as a carefully planned approach to make sure the safety of consumers is protected. However, it is more likely that a complete substitution of cnvironmentally damaging halogenated 
refrigerants by natural refrigerants is largely dependent on more restrictive regulations on the use of the former category of refrigerants on a much larger scale.

\section{a) ISO 5149 - Mechanical refrigerating systems used for cooling and heating - Safety requirements}

This international standard specifies the requirements relating to the safety of persons and property for the design, construction, installation and operation of refrigerating systems. It gives a classification of the refrigerating systems. Applies to all,types of refrigerating systems in which the refrigerant is evaporated and condensed in a closed circuit, including heat pumps and absorption systems, except for systems using water or air as the refrigerant. Also applicable to new refrigerating systems, extensions and modifications of already existing systems, and for used systems.

ISO 5149, under the general title Refrigerating systems and heat pumps - Safety and environmental requirements, consists of the following parts

Part 1: Basic requirements, definitions, classification, and selection criteria,

Part 2: Design, construction, testing, marking, and documentation,

Part 3: Installation site,

Part 4: Operation, maintenance repair and recovery.

\section{b) ISO 817 - Refrigerants: Designation and safety classification}

This standard provides an unambiguous system for numbering and assigning composition-designating prefixes to refrigerants. Tables listing the refrigerant designations are included along with a means for determining refrigerant concentration limits.

This standard is to be used with other relevant safety standards, such as: ISO 5149 (1993), IEC 60335-2-24, IEC 60335-2-40 (1995) (details given under $c$ next).

c) EN 60335 - Specification for safety of household and similar electrical appliances. General requirements
The EN 60335 standard is a series of standards for the safety of household and similar electrical appliances. EN 60335 for safety comes in two parts, EN 60335-1, which encompasses general safety requirements, and EN 60335-2, which covers specific safety requirements for household and similar electrical appliances. EN 60335-2 standards carry specific safety standards for a number of individual products. Under this, following standards are more specifically applied to HC refrigeration systems; 60335-2-24 (Household and similar electrical appliances - Particular requirements for refrigerating appliances, ice-cream appliances and ice-makers), IEC 60335-2-40 (Household and similar electrical appliances Particular requirements for electrical heat pumps, air-conditioners and dehumidifiers) and, IEC 60335-2-89 (Household and similar electrical appliances - Safety Particular requirements for commercial refrigerating appliances with an incorporated or remote refrigerant condensing unit or compressor).

In all, complete testing to EN 60335 fulfills the safety requirements of the European Union for household and similar electrical appliances.

\section{d) Refrigerant charge limits}

Limiting the amount of refrigerant charge within a single refrigerant circuit is one approach for achieving an approximate level of safety. The existing standards, except for ISO 5149 (1993), incorporate this methodology, where as the latter has only very specific situations for applications of HC. However, the draft international standard of ISO 5149 (2006) has been revised to address the issues of HCs.

According to the above standards (which cover both safety and environmental requirements) HCs are classified as A3 working fluid - i.e. flammable fluid. The maximum refrigerant charge for these fluids depends on the occupancy category (general, supervised or authorised access only) and on the location of the refrigerant containing parts (entire system within occupied area, compressor and receiver outside, all refrigerant containing component outside the occupied area).

For example, according to ICE 60335-2-40, for a comfort heating or cooling application for general occupancy (such as lecture room, restaurant or house), the maximum allowable 
amount of hydrocarbon in the refrigeration circuit would be $1 \mathrm{~kg}$. The key idea behind the restrictions on the amount is to encourage system developments that would use minimum amounts of refrigerant.

\section{e) Safe design and construction}

In addition to the described limitations on the maximum refrigerant charge depending on the size of the room and type of occupancy, the standards impose requirements on any aspect of the refrigeration system itself that could become a risk due to the refrigerant flammability. Under such requirements the followings are generally included.

a) Materials must be selected to support foreseeable mechanical, thermal and chemical tensions.

b) In piping, non-permanent joints are not allowed in occupancy areas. Refrigerant tubing shall be protected or enclosed to avoid mechanical damage and shall not be used during handling or transport.

c) In the case of secondary fluid based systems, due to any break of evaporator or condenser, the heat exchangers shall not allow the release of the refrigerant into the areas served by the secondary heat transfer fluid.

d) A refrigerant detector shall function at a level not exceeding $20 \%$ of the lower flammability limit, which shall continue to activate at higher concentrations and automatically activate an alarm, start mechanical ventilation and stop the system when triggered.

\section{Summary}

Hydro carbons receive increased consideration in the refrigeration, air conditioning and heat pump industry as a category of natural, environmentally friendly refrigerants. Being natural fluids $\mathrm{HCS}$ has a number of positive aspects compared to halogenated refrigerants; common availability and no monopolies, no apparent refrigerant recycling, good availability etc., are just few to mention. However, the flammability of $\mathrm{HCs}$ in general put many potential users and uses (applications) off due to the safety risk associated with HCs.
In Europe there is a wide acceptance of HCs as refrigerant which is slowly crossing the boundaries to other counties due to legislations in place that globally restrict the use of HCFCs/HFCs. Good thermal performances, comfortable levels of behavior with common lubricants, possibility of going for compact systems with less amount of charge make HCs more attractive for smaller refrigeration units, however, that does not limit their use for large industrial applications, where blending of HCs could deliver specific process requirements. All in all, provided proper management and regulations in place to make sure sensible and safe use, HCs provide a class of energy efficient natural working fluids with a long term future in the industry. The key to mitigate the safety issues associated with the flammability is to minimize the system charge by way of having compact systems and to place the main system hardware outside whenever practically possible.

\section{References}

1. Jose M. Corberana, Jacobo Segurado, Daniel Colbourne, Jose' Gonza'lvez, Review of standards for the use of hydrocarbon refrigerants in $\mathrm{A} / \mathrm{C}$, heat pump and refrigeration equipment, lnt J of Refrigeration, 2008 (31), 748-756.

2. Akio Miyara, Condensation of hydrocarbons A review, Int Tounal of Refrigeration, 2008, (31) $621-632$

3. Bjorn Palm, Hydrocarbons as refrigerants in small heat pump and refrigeration systems - A. review, Int J of Refrigeration, 2008 (31), 552-563.

4. Report of the refrigeration, air conditioning and heat pumps technical committee, 2006 Assessment, United Nations Environmental. Program (UNEP)

5. Tadros, A., Clark, J.W., Maclaine-Cross, I.I., Leonardi, E., 2006. Replacing fluorocarbons with hydrocarbon mixtures in centrifugal water chillers. In: Proceedings of the Seventh IIR-Gustav Lorentzen Conference on Natural Working Fluids, Trondheim.

6. Guidelines for the use of Hydrocarbon Refrigerants in Static Refrigeration and Air Conditioning Systens from, Air Conditioning and Refrigeration Industry Board (ACRTB), United Kingdom, 2001.

7 David P. Wilson, Robert G. Richard, Determination of Refrigerant Lower 
Flammability Limits in Compliance with Proposed Addendum $p$ to Standard 34, ASHRAE Transactions, 2002, (108), Part 2, 739756

8. Dongsoo Jung, Chong-Bo Kim, Kilhong Song, Byoungiin Park, Testing of propane/isobutane mixture in domestic refrigerators, hit Journal of Refrigeration, 2000, (23) 517-527

9. John R. Thomea, Lixin Cheng, Gherhardt Ribatski, Luiz F. Vales, Flow boiling of ammonia and hydrocarbons: A state-of-the-art review, Int Joumal of Refrigeration, 2008, (31) $603-620$

10. Mao-Yu Wen, Ching-Yen Ho, Evaporation heat transfer and pressure drop characteristicsof R-290 (propane), R-600 (butane), and a mixture of R-290/R-600 in the three-lines serpentine small-tube bank, Applied Thermal Engineering, 2005 (25) 2921-2936.

11. Ho-Saeng Lee, Jung-In Yoon, Jae-Dol Kim, P.K. Bansal, Characteristics of condensing and evaporating heat transfer using hydrocarbon refrigerants, Applied Thermal Engineering, 2006 (26) 1054-1062

12. Mao-Yu Wen, Ching-Yen Ho, Jome-Ming Hsich, Condensation heat transfer and pressure drop characteristics of R-290 (propane), R-600 (butane), and a mixture of R290/R-600 in the serpentine small-tube bank, Applied Thermal Engineering, 2006 (26) 20452053.

13. Mao-Yu Wena, Ching-Yen Ho, Condensation heat-transfer and pressure drop characteristics of refrigerant R-290/R-600a-oil mixtures in serpentine small-diameter U-tubes, Applied Thermal Engineering, article in press, doi:10.1016/j.applthermaleng.2008.12.014

2009.

14. Mao-Yu Wen, Ching-Yen Ho, Jang-Kuen Jang, Boiling heat transfer of refrigerant $R-600 a / R$ 290-oil mixtures in the serpentine smalldiameter U-tubes, Applied Thermal Engineering, 2007 (27) 2353-2362

15. S. Devotta, A.V. Waghmare, N.N. Sawant, B.M. Domkundwar, Alternatives to HCFC-22 for air conditioners, Applied Thermal Engineering, 2001, (21) 703-715

16. D.J. Cleland, R.W. Keedwell, S.R. Adams, Use of hydrocarbons as drop-in replacements for hcfc-22 in on-farm milk cooling equipment, in press, Int Joumal of Refrigeration, 2009, 10.1016 /j.ijrefrig. 2009.02.004.
17. Devotta, A.S. Padalkar, N.K. Sane, Performance assessment of $\mathrm{HC}-290$ as a drop-in substitute toHCFC-22 in a window air conditioner, Int Joumal of Refrigeration, 2005 (28) 594-604

18. M.A. Alsaad, M.A. Hammad, The application of propane/butane mixture for domesticRefrigerators, Applied Themal Engineering, 1998 (18) $911-918$

19. Moo-Yeon Lee, Dong-Yeon Lee, Yongchan Kima, Performance characteristics of a smallcapacity directly cooled refrigerator using R290/R600a (55/45), Int Joumal of Refrigeration, 2009, (31) 734-741 
Appendix $\quad 1$ - Selected International standards relating to refrigeration systems [1]

1 EN 378: 2000). Refrigerating systems and heat pumps - Safety and environmental requirements

2. IEC 60335-2-24. Safety of household and similar electrical appliances - Part 2-24: Particular requirements for refrigerators, food-freezers and ice-makers.

3. IEC 60335-2-34. Safety of household and similar electrical appliances - Part 2-34: Particular requirements for motor compressors

4. IEC 60335-2-89. Safety of household and similar electrical appliances - Part 2-89: Particular requirements for commercial refrigerating appliances with an incorporated or remote refrigerant condensing unit or compressor

5. IEC 60335-2-40. Safety of household and similar electrical appliances - Part 2-40: Particular requirements for electrical heat pumps, air conditioners and dehumidifiers.

6. TS 95006: 1995. Refrigerators, foodfreezers and ice-makers using flammable refrigerants. Safety requirements. Amendment to IEC60335-2-24.

7 IEC 60079: 2001. Electrical apparatus for explosive gas atmospheres.

8. ISO 5149: 1993. Mechanical refrigerating systems used for cooling and heating Safety requirements.

9. ASHRAE 34-1992. USA. Number Designation and Safety Classification of Refrigerants.

10. ASHRAE 15-1994. USA. Safety Code for Mechanical Refrigeration.

11. DIN 7003. Germany. Refrigeration Systems and tuat Pumps with Flammable Relrigerants of Group L3 - Safety Requirements.

12. BS 4434:1995. United Kingdom. Specification for safety and environmental aspects in the design, construction and installation of refrigelating appliances and systems.

13. NPR 7600. Netherlands. National Code of Practice for flammable refrigerants.

14. ACRIB Guidelines 2001. United Kingdom. Guidelines for the use of hydrocarbon refrigerants in static refrigeration and airconditioning systems.

15. IOR Safety Code of Practice for A2 and A3

Refrigerants. 2007 Institute of Refrigeration. United Kingdom. 